2-27-2004

\title{
Evaluation of Needle Exchange Programs
}

Cheryl Delgado

Cleveland State University, c.delgado@csuohio.edu

Follow this and additional works at: https://engagedscholarship.csuohio.edu/nurs_facpub

Part of the Nursing Commons

How does access to this work benefit you? Let us know!

Publisher's Statement

This is the accepted version of the following article:Delgado, C. (2004). Evaluation of needle exchange programs. Public Health Nursing, 21(2), 171-178. doi:10.1111/

j.0737-1209.2004.021211.x , which has been published in final form at http://onlinelibrary.wiley.com/doi/10.1111/j.0737-1209.2004.021211.x/abstract

\section{Recommended Citation}

Delgado, Cheryl, "Evaluation of Needle Exchange Programs" (2004). Nursing Faculty Publications. 11. https://engagedscholarship.csuohio.edu/nurs_facpub/11

This Article is brought to you for free and open access by the School of Nursing at EngagedScholarship@CSU. It has been accepted for inclusion in Nursing Faculty Publications by an authorized administrator of EngagedScholarship@CSU. For more information, please contact library.es@csuohio.edu. 


\section{Evaluation of Needle Exchange Programs Cheryl Delgado, M.S.N., R.N.}

\begin{abstract}
Needle exchange programs exist in every major population area in the United States and in many other countries. Some operate legally under emergency health decrees issued by local departments of health, with the stated intention of risk reduction through the removal of used injection equipment from use by injection drug users. It is theorized that this results in a reduced transmission of human immunodeficiency virus, hepatitis, and, possibly, other blood-borne diseases. Needle exchange programs also offer access to drug treatment programs for the participants. It is a difficult but necessary task to evaluate these programs. This article examines examples of evaluations attempted in the past and discusses the challenges of such evaluations. Experimental evaluations, economic program analysis, legal aspects, and risk-benefit assessment along with ethical aspects are considered. An outline of program evaluation is proposed. Needle exchange programs offer an opportunity to encourage risk reduction and to offer counseling and access to health care for individuals at high risk. It is essential that such programs demonstrate their effectiveness. Assumptions of efficacy are insufficient for health care in the twenty-first century.
\end{abstract}

Key words: needle exchange, program evaluation, AIDS, hepatitis.

Needle exchange programs (NEPs) are not uncommon in urban America. Programs exchange used syringes for unused syringes in intravenous drug users to prevent the reuse of contaminated injection equipment. Other materials may be provided by NEPs, including bleach bottles, cotton swabs, skin ointment, condoms, and educational handouts about human immunodeficiency virus (HIV)/ acquired immunodeficiency syndrome (AIDS), sexually transmitted infections, and other communicable illnesses.
The purpose of the exchange and supply of such items is to reduce the risk of transmission of communicable disease by the intravenous drug user. Most NEPs combine a program goal of risk reduction through needle exchange with a program goal of offering counseling and referral of participants to drug treatment programs.

NEPs commonly operate under local department of health emergency orders. Chief officials of local health districts are charged with public safety. They have authority to issue orders for the protection of the public health through the prevention of disease or restriction of the spread of disease. Orders from such officials authorizing the legal operation of the NEP are a response to the epidemic of HIV infection among injection drug users (IDUs). Authorization orders that are issued under a state public health code typically follow this format: Step 1, a health emergency is declared; Step 2, the local spread of HIV through drug use is described; Step 3, evidence of NEPs as an effective preventative measure is provided; Step 4, the emergency is periodically redeclared for the continued operation of the program (Burris, Finucane, Gallagher, \& Grace, 1996). This conditional and emergency nature of the authorization will often be stated in the general description of the program for the political authorities that provide legal cover for the activity of the exchange program. Programs emphasize the protective nature of the exchange for the public at large.

Rules and regulations for the NEP usually mandate the existence of a demonstrable infrastructure and a physician director who is readily available in the local area. Participants are commonly limited to adults 18 years and older, with identification cards for proof of participation. Program staff is also usually identified. Other regulations are to ensure participant confidentiality and staff and participant safety, training regarding blood-borne pathogens and CPR, and the capability of the staff to provide one-on-one education for HIV and risk-reduction behaviors. Exchange sites are generally not allowed close to schools, 
churches, playgrounds, and day care or recreation centers, and programs must maintain a regular schedule with identified sites for the exchanges. An NEP which operates as a medical facility must provide HIV testing, counseling for risk reduction, referral for other medical and social services, and substance abuse assessments with links to drug treatment facilities. In addition, liability insurance is often required.

\section{DISCUSSION OF LEGAL ASPECTS}

Legal issues for NEPs center on drug paraphernalia. Possession and delivery of drug paraphernalia is illegal in 46 states and the District of Columbia (Burris et al., 1996). Most of these laws are based on a model from the United States Drug Enforcement Agency written in 1979 that criminalized the manufacture, possession, and distribution of drug paraphernalia. Drug paraphernalia is loosely defined to include any equipment, product, or material intended to be used to introduce an illicit substance into the body. Intent is an important aspect of this law, as it transforms ordinary items like bleach, cotton balls, and paper clips from household items into drug paraphernalia. Materials supplied by programs are paraphernalia, and therefore, trafficking in them could be illegal. Some states require a prescription for syringes, and possession of them without prescription is a criminal offense (Webber, 1997).

According to Burris et al. (1996), current programs for syringe or needle exchange fall into two broad categories: illegal and legal. The illegal programs operate without legal basis, and participants are subject to prosecution. Legal programs operate in areas where there is no local drug law, or by indirect authorization through amendment or judicial interpretation of drug laws. Direct authorization allows NEPs in Cleveland, Philadelphia, Los Angeles, San Francisco, and six other areas in California to claim legality based on local interpretation of state public health or drug laws. Courts generally defer to public health officials and rarely overturn necessary actions taken to prevent the transmission of disease. Examples include mandatory vaccinations, testing for some sexually transmitted diseases, prophylactic eye treatments for newborns, and even fluoridation of water supplies. All states have laws that require and empower public health officials to protect the public (Burris et al., 1996). Programs with no or shaky legal support operate because of the tolerance of law enforcement and political leaders. They may tacitly support NEPs, although not be willing to act openly. Also, NEPs may not be considered an important enough activity to merit police attention.
Law enforcement agencies are more interested in apprehending dealers than identifying users.

\section{ETHICAL ISSUES AS A RISK-BENEFIT EVALUATION}

According to Loue, Lurie, and Lloyd (1995), an ethical assessment requires consideration of four elements: beneficence versus maleficence, respect of persons (autonomy, dignity, and confidentiality), justice and fairness, and utilitarianism. Few drug treatment programs have long-term success, and many drug users do not seek treatment. The principle of risk reduction accepts that a dangerous behavior like intravenous drug use is inevitable. Health officials therefore have a responsibility to the general public to reduce risks associated with the acts (drug use) they cannot prevent. Risk reduction is a more reasonable goal than attempts to eradicate illegal intravenous drug use. NEPs benefit participants by reducing the risk of disease (HIV/AIDS and hepatitis) in IDUs by providing clean injection equipment. Risks of HIV/AIDS and associated diseases are reduced in the sex partners and children born of the IDU as well. NEPs may be used to access counseling, testing, and treatment services, and dirty injection equipment is collected rather than haphazardly discarded in the community. Some studies have concluded that an NEP that is easily accessed by the IDU will replace black-market sources (Watters, Estilo, Clark, \& Lorvick, 1994). There is then reduced risk not only to the intravenous drug user but also to other members of the immediate community and to society in general, in terms of the potential limitation of the spread of communicable disease, specifically hepatitis, tuberculosis, and HIV.

Those opposed to NEPs argue that it is harmful (maleficent) to provide injection equipment as it condones and may encourage intravenous drug use that is an illegal, self-destructive act. Many feel that the time, money, and energy expended in NEPs would be better spent on treatment programs that are chronically underfunded. Others, who do not receive free clean needles but require them for the treatment of chronic illnesses such as diabetes, ask whether it is a justifiable or fair allocation of limited resources.

For an NEP to be useful to the public (utilitarianism) and satisfy the purpose of the emergency order, local conditions must be taken into consideration. Neighbors to an exchange site may feel a disproportionate impact from the NEP in their area. Drug traffic may increase in the area of the exchange site. No studies have addressed this particular question, although studies have concluded that crime rates, in general, are not affected by the operation of an NEP 
(Marx et al., 2000). Loue et al. (1995) wrote that "even for drug users who continue to inject, rates for drug related crimes will be somewhat reduced due to IDU's decreased need for the funds to purchase or lease paraphernalia to inject drugs" (p. 383). This is an optimistic statement considering that the main expense of the IDU is the drug and not the equipment. A study by Watters et al. (1994) was able to conclude only that the availability of clean injection equipment reduced needle sharing and associated disease but did not impact on drug use itself. A more recent study has indicated that needle exchange alone may not be enough to reduce risks of disease spread by blood-borne viruses. Other equipments involved in the preparation and dividing of drugs may be sources of contamination (Hagan $\&$ Theide, 2000). Discards of contaminated needles may be decreased (beneficence) in the local area, according to one study (Loue et al., 1995), or are at least not increased, according to Doherty et al. (2000). A major community concern is redistribution of needles provided by the NEP.

The question of local neighborhood autonomy also arises. Harlan Dalton, quoted from "AIDS in Blackface," Daedalus 1989 in Stryker and Smith (1993) is eloquent.

\begin{abstract}
"For us (African-Americans) drug use is a curse far worse than you can imagine. Addicts prey on our neighborhoods, sell drugs to our children, steal our possessions, and rob us of hope. We despise them. ... Why can't we choose which of the many problems facing us to tackle first? Suppose we think that crack is more of a menace than AIDS. Are you willing to help us take that one on? Why do you want us to take all the risks?
\end{abstract}

\section{PROGRAM EVALUATION CHALLENGES}

The evaluation of controversial programs such as an NEP is a challenge but essential for politicians and granting agencies who need a sound basis for decisions, not only for funding and grant appropriations but also for the legal manipulations necessary for continued operation. Within the NEP, management decisions regarding budget allocation and resource utilization must be made. A program evaluation answers the question "What is the effect of the program?"

The scope of a program may be a problem for evaluators. The geographic area may be large and poorly defined or even impossible to define. Do the effects of a program stop at the city or county lines? If the program evaluates in terms of population rather than geographic area, what is that population? Who is included, excluded, and why? The quality of the program goals will have a significant effect on the evaluation. Are the goals clear and precisely stated? Are they measurable? Goals that are vague or global in nature may require a discussion of the concepts involved, so that the evaluators and the program actors are in agreement.

The politics of an evaluation must also be considered. Varied stakeholders have different interests in the program and may have an influence on the evaluation, even inadvertently. The concerns of all stakeholders should be included in planning evaluations, so that all concerns are addressed and none is disproportionately represented. In any evaluation scheme, the clarity and specification of the program goals in the planning and pre-implementation stage is important.

Mateo and Kirchoff (1999) see program evaluations as formative or summative. Formative evaluations assess, report, and monitor the implementation and progress of a program. A well-defined purpose for the program, realistic goals, and measurable variables of interest are needed. Formative evaluations may also look at specifics of the program operation, such as staff training. Summative evaluations assess the effectiveness of the program after the desired change has been implemented. The questions answered by a summative evaluation included whether or not the goals of the program were accomplished, whether the purpose of the program was upheld, and whether there were any unanticipated results from the program change. A summative evaluation could compare the program results with other similar interventions.

Experimental evaluative designs are expensive and difficult to design in terms of control group and random assignments. They may also be unethical if they do not use or if they exclude the use of other related pre-existing programs. Experimental designs tend to be artificial in the degree of control in a setting and may not provide insight into the real world where a program operates. It may be impossible to understand and isolate the effects of all possible influence variables in a community setting. Evaluations may use experimental, quasi-experimental, cross-sequential, and descriptive methods. Both qualitative and quantitative methods of data collection are useful. Brink and Woods (1998) assume the following in any evaluative design:

1 measurable objectives for the program that can be used as a basis for evaluation;

2 methods or tools available to measure the variables;

3 objectives prioritized according to their value to the program;

4 control participants in adequate numbers for statistical tests to be significant.

\section{EXAMPLES OF NEEDLE PROGRAM EVALUATIONS}

The overall intention of NEPs and the justification for the legal machinations necessary to operate exchange 
programs in the United States is the protection of the general public against the spread of blood-borne viral disease, specifically HIV and hepatitis. A secondary goal is the contribution to the control of other infectious diseases, such as tuberculosis. A pure experimental evaluation of that relationship is impossible, but quasiexperimental studies have been performed, with conflicting results. Bruneau et al. (1997) found an increase in HIV rates among participants in the programs evaluated, but this was not the case for Hurley, Jolley, and Kaldor (1997), who found a decrease in HIV seroconversion among participants in their study. No one has made the attempt to relate the program under study to HIV incidence in the general population rather than the direct program participants, even though such a benefit is often a stated goal. This makes the inclusion of such a goal suspect as a political maneuver rather than a true aim of the program. It is no doubt successful as an instrument in obtaining initial approval for an exchange program (what politician would stand against a program purported to prevent the spread of a dread disease to innocent voters), but it is unmanageable as an outcome measure and could backfire if program opponents take the position that reduction of infection rates in the general population is a criteria for continued support of the program.

Cohort studies have been used in NEP evaluations. Experimental studies for program evaluation are difficult to design. Obtaining informed consent of the participants would be a challenge, and the potential for bias would be considerable. Both Bastos and Strathdee (2000) and Hagan et al. (2000b) indicate that selection factors often lead to over-representation of high-risk drug users in NEPs. Although Des Jarlais, Dehne, and Casabona (2001) state that it will probably never be possible to obtain a true random sample from an IDU population, they believe that it is possible to locate and conduct research with IDUs. They suggest that research studies for monitoring the prevalence of a disease (surveillance studies) should include assessment of risk behaviors, because reports of infection rates alone may not be sufficiently time sensitive. This seems especially true in diseases such as AIDS, where a decade or more may ensue between infection and the onset of active disease. The primary risk behaviors of the target group to be measured would be the sharing of drug injection equipment, the potential for rapid turnover of partners, and the incidence of high-risk sexual practices, as well as other demographics such as the size of the target population, their patterns of drug use, and their participation in prevention activities and access to treatment programs. The design was strong in that it combines both formative and summative measurements.
The ideal experimental evaluation would be a longitudinal study that followed up a cohort of IDUs for an extended period of time after baselines measurements were established for these behaviors and compared them with equivalent control group of IDUs who did not participate in the program. In reality, such a plan would be impossible to implement, not only because of the expense or ethical concerns involved (which alone are colossal), but because it would be impossible to insulate the study from cultural, economic, and societal changes, in general, that would confound the data. This was demonstrated in a longitudinal study (Van Ameijden \& Coutinho, 2001) conducted in The Netherlands with an open cohort study from 1986 to 1998, using a total of 996 drug users recruited during that time and 4-month follow-ups. Generalized estimating equations used for statistical analysis revealed a decrease in injected drug use but noted an increase in noninjected drug use. Mortality and migration explained one-third of the decrease in injection drug use, and the study concluded that the decrease in injection drug use was not related to the large-scale needle program but to ecologic factors of the drug culture and market. During that historical period, cocaine, not injectable drugs, became popular among users.

The demographics of NEP participants were profiled by Belanger et al. (2000). This may be useful to planners of programs and in the evaluation of whether or not the target population had been affected by the program.

A cohort study in Seattle (Hagan et al., 2000a) was carried out for a 12-month period, examining the relationship between needle exchange and enrolment and retention in methadone drug treatment. Participant entry to drug treatment programs is often a stated goal of NEPs and could be an outcome variable for summative evaluation. This study did find that new users of the program were five times more likely to enter drug treatment, and the assumption was made that drug use was reduced and that the public, thereby, benefited from the prevention of blood-borne viral disease transmission, although this was not specifically addressed in the study.

Most often, program goals are global, idealistic, and difficult to measure. A more practical approach is the formative evaluation that examines the process of implementation and operation of the program. The evaluator may look at steps taken to reduce the risk of the spread of infection rather than the prevalence of the disease itself in a community. Disease rates may have many contributing factors, and it may not be possible to isolate the impact of a particular program. A program that looks at changes in constituent behaviors related to a disease may find them more measurable. For NEPs, this is often a determination 
of the program's impact on needle-sharing behavior among participants.

Marmour, Shore, Titus, Chen, and Des Jarlais (2000) found a decreased acceleration of injection habits among participants in an NEP in New York City. Other behaviors of IDUs such as sharing or reuse of injection equipment were examined by several researchers including Heimer, Khoshnood, Bigg, Guydish, and Junge (1998), Guydish, Bucardo, Clark, and Bernheim (1998), and Blumenthal, Kral, Gee, Erringer, and Edlin (2000). Risk reduction by this mechanism is often a stated goal of NEPs. All researchers found that this behavior was reduced in program participants. One study (Broadhead, van Hulst, \& Hecksthorn, 1999) found that the closing of an NEP resulted in an increase in the incidence of highrisk sharing behaviors by former participants.

\section{PROGRAM ANALYSIS-ECONOMIC ASPECTS}

Politics, in general, have had an impact on the evaluation of NEPs in the United States. Because no federal funds have been available for studies, most information about the effectiveness of programs has come from Europe and Canada. This financial bias existed both in the recent Democratic administration and in the current Republicancontrolled Congress. It is not likely to change at the federal level.

NEPs receive operating funds from four general sources: local governments, foundation grants, private donation, and activist or community organizations that run NEPs. Most programs require more than one source. Federal law prohibits funding of NEPs (Webber, 1997), and local officials who tacitly accept what they see as the necessary evil of needle exchange are seldom willing to provide much sought after public money. Still, of 13 legal programs surveyed by Lurie and Chen (1993), only one was without direct or indirect government funds.

More substantial funding comes from foundation grants - on a national level, the American Foundation for AIDS Research (AmFAR) and the Robert Wood Johnson Foundation. AmFAR has also been used to distribute government funds. Often, grant money from foundations is seed money for the purpose of initial setup or demonstration. Donations from private persons, through fund-raisers (solicitation, dinners, and concerts), are a major source of money but only in the United States. Programs relying on money from local donation or activist support are less likely to be legally based (Lurie \& Chen, 1993).

General operating budgets are made up of corporate donations, foundation grants, individual donations, and funds from special events. Limited funds must be spent in the most cost-effective way, and controversial programs will need to justify costs to sponsors. Some donations may be lost because of the NEP, and the effects of this would have to be factored into any costbenefit analysis. Reid (2000) advocates the use of costbenefit analysis for evaluations of NEPs, yet this is difficult to do when the needle exchange produces no revenue or easily measurable benefit to balance with costs.

The real economics of an NEP are difficult to calculate. What value can be assigned to prevention? How does one accurately measure the number of people who do not get AIDS from contaminated needle use? We can estimate the number of IDUs in a target population and relate this to estimates that the HIV infection rate of IDUs is approximately $50 \%$, with additional infections in their sex partners and children (Loue et al., 1995). The costs of drug treatment, medical care, supportive social programs, and other nondirect costs can be calculated. These calculations do not include associated diseases such as tuberculosis or hepatitis, but that could be done. A study by Pearlman et al. (2001) examined the costs of tuberculosis screening associated with an NEP in New York City and found that net savings made the program cost-effective, as compared with treating active cases of tuberculosis.

In Canada, Jacobs et al. (1999) calculated that the value of a 1-year delay in HIV infection was worth $\$ 9,500$ per case. Another Canadian study conducted by Gold, Gafni, Nelligan, and Millso (1997) estimated that the HIV incidence rate would be decreased from 4 to $2 \%$ by the program and that with 275 participants, 24 cases of HIV would be prevented over a 5 -year period. Estimating the lifetime costs of health care for AIDS patients, but omitting the indirect costs associated with lost productivity and costs incurred by informal caregivers, it was a conservative prediction that the program studied would provide a cost saving of $\$ 1,300,000$ (Canadian dollars) after accounting for program costs.

Just as the opening and operation of an NEP in a community should be carefully negotiated with the residents of the area, local politicians and other leaders, evaluation of the program needs to be done with participation of these stakeholders. Even well-supported scientific evidence will not stand against community perceptions of risks and benefits. Focus groups comprised of clergymen, educators, local health care providers, and interested area citizens would provide important information about impact of the program on the community. Health care facilities and educational institutions in the area should co-ordinate services and facilities and tailor programs for specific local needs. 


\section{A PROPOSAL FOR PROGRAM EVALUATIONS}

Monitoring the prevalence of HIV and hepatitis infection in IDUs should be done, even though this is not likely to provide support for the program. Because disease rates have been used as justification for many programs, a significant change in disease rates, from any cause, would mandate reexamination of the program goals and purpose.

On an operational level, the following steps could be valuable.

1 Initial steps of the evaluation:

- The program must document compliance with all rules and regulations of the authorization order.

- Surveys should be regularly carried out to monitor the training status and activities of the program staff to ensure that they are following the process outlined by the program (record keeping, utilization of negotiated sites, etc.). A $\log$ of problems needing attention could be established and discussed at regularly scheduled staff meetings. Staff should also be encouraged to share ideas regarding ways to improve the program.

- Records should be reviewed to determine program usage by participants.

2 Measuring the variables of interest:

- Workers who have established some relationship with program participants could be trained to collect qualitative (interview) data regarding drug-use trends, needle- and equipment-sharing activity, and lifestyle, including high-risk sexual behaviors of the participants. Process variables such as number of participants, number of return participants, number of participants entering drug treatment, and number of participants utilizing other health services (medical care and psychological counseling) should be tracked on an ongoing basis.

- Focus groups comprised of community leaders should be utilized to monitor the community image of the program and identify any unanticipated effects of the program.

3 Data collection and analysis:

- Narrative accounts of program implementation and function from staff meeting minutes will give an account of how well the program is being run. Narrative data will need analysis for explication of recurrent or meaningful observations and problems. In this manner, a qualitative process evaluation can be made.

- Quantitative and qualitative data regarding the usage of services should be collected without disruption of services. Quantitative data would document current service usage. Qualitative data would give insight into how current services are received by drug users and provide some anecdotal support for effectiveness. Information should be collected in a systematic and uniform manner, so that appropriate statistical analyses may be made with confidence. Information should be coded to preserve anonymity of participants.

4 Evaluating data analysis:

- Evaluations should be carried out by uninterested parties rather than by stakeholders to eliminate bias.

- Cost-benefit analysis should be attempted despite inherent challenges, using best-guess estimates (clearly identified as such) when necessary.

Program evaluations can be difficult and time consuming. Often, program goals change or evolve during the course of a program or are ambiguously stated. Planning how program evaluation will be carried out should occur early in the development of a program and should focus on the issues important to the administrators of the NEP. Without knowledge of the focus of a program, it is possible that an evaluation may miss unanticipated effects of the program that might be beneficial. In a goal-free evaluation, there is an examination of the overall effect of the program, rather than an evaluation based on a priori goals. All evaluation programs must be formulated to match the program to be evaluated. There is no one right method or design. A good overview of evaluative research designs is provided by Portney and Watkins (2000) in their text Foundations of Clinical Research. Another good resource for those planning a program evaluation for an NEP would be Mateo and Kirchoff's (1999) Using and Conducting Nursing Research in the Clinical Setting.

\section{CONCLUSIONS}

More outcome research is needed on NEPs, but there are many challenges. Academic institutions may not be supportive of this type of research because of the controversial nature of the programs. Institutional review boards may not approve projects involving acts of questionable legality. Funding for research could be scarce for the same reason. Research in this area may not be considered scholarly or worthy of investigation, and design of research studies would be a challenge. NEP participants are self-selected, making randomization, bias, and control major concerns. 
The National Academy of Sciences, the National Commission on AIDS, the General Accounting Office of the United States, and the University of California under the sponsorship of the Center for Disease Control have attested to NEP efficacy. Center for Disease Control concludes that NEPs are "likely to reduce HIV transmission" and "no evidence of any NEP related increases in community levels of drug use" (anon., in Loue et al., 1995). The growing number of NEPs indicates increased acceptance. As an opportunity to encourage risk reduction and to offer counseling and access to health care for individuals at high risk, NEPs should not be overlooked. Yet, the emphasis on cost-effective interactions makes it essential that these programs be able to demonstrate their effectiveness with proven outcome evaluations. Assumptions of efficacy are insufficient for providers and users of health care services in the twenty-first century.

\section{REFERENCES}

Bastos, F. I., \& Strathdee, S. A. (2000). Evaluating effectiveness of syringe exchange programs: current issues and future prospects. Social Science \& Medicine, 51(12), 1771-1782.

Belanger, D., Noel, I., Alary, M., Parent, R., Poulin, C., \& Claessens, C. (2000). Drugs, poverty and HIV: results regarding a provincial needle exchange program in Point De Reperes, Quebec. Canadian Journal of Public Health, 91(3), 176-180.

Blumenthal, R. N., Kral, A. H., Gee, L., Erringer, E. A., \& Edlin, B. R. (2000). The effect of syringe exchange on high-risk injection drug users: a cohort study. AIDS, 14(5), 605-611.

Brink, P. J., \& Woods, M. J. (1998). Advanced design in nursing research (2nd ed.). Thousand Oaks, CA: Sage.

Broadhead, R. S., van Hulst, R. S., \& Hecksthorn, D. D. (1999). The impact of a needle exchange's closure. Public Health Reports, 114(5), 439-447.

Bruneau, J., Lamothe, F., Franco, E., Lachance, N., Desy, M., Soto, J., \& Vincelette, J. (1997). High rates of HIV infection among injection drug users participating in needle exchange programs in Montreal: results of a cohort study. American Journal of Epidemiology, 1146(12), 994-1002.

Burris, S., Finucane, D., Gallagher, H., \& Grace, J. (1996). The legal strategies used in operating syringe exchange programs in the United States. American Journal of Public Health, 86(8), 1161-1165.

Dalton, H. (1993). AIDS in Blackface. In J. Stryker \& M. D. Smith (Eds.), Dimensions of HIV Prevention: Needle Exchange. Menlo Park, CA: Henry J. Kaiser Family Foundation.

Des Jarlais, D. C., Dehne, K., \& Casabona, J. (2001). HIV surveillance among injecting drug users. AIDS, 15(3), $\mathrm{S} 13-\mathrm{S} 22$.

Doherty, M. C., Junge, B., Rathouz, P., Garfein, R. S., Riley, E., \& Vlahov, D. (2000). The effect of a needle exchange program on numbers of discarded needles: a two year follow up. American Journal of Public Health, 90(6), 936-939.

Gold, M., Gafni, A., Nelligan, P., \& Millso, P. (1997). Needle exchange programs: an economic evaluation of a local experience. Canadian Medical Association Journal, 157(3), 255-262.

Guydish, J., Bucardo, J., Clark, G., \& Bernheim, S. (1998). Evaluating needle exchange: a description of client characteristics, health status, program utilization and HIV risk behavior. Substance Use \& Misuse, 33(5), 1173-1196.

Hagan, H., McGough, J. P., Theide, H., Hopkins, S., Duchin, J., \& Alexander, E. R. (2000a). Reduced injection frequency and increased entry and retention in drug treatment associated with needle exchange participation in Seattle drug injectors. Journal of Substance Abuse Treatment, 19(3), 247-252.

Hagan, H., McGough, J. P., Theide, H., Hopkins, S. G., Weiss, N. S., \& Alexander, E. R. (2000b). Volunteer bias in unrandomized evaluations of the efficacy of needle exchange programs. Journal of Urban Health, 77(1), 103-112.

Hagan, H., \& Theide, H. (2000). Changes in injection risk behavior associated with participation in the Seattle needle exchange program. Journal of Urban Health, 77(3), 369-382.

Heimer, R., Khoshnood, K., Bigg, D., Guydish, J., \& Junge, B. (1998). Syringe use and reuse: effects of syringe exchange programs in four cities. Journal of Acquired Immune Deficiency Syndromes and Human Retrovirology, 18(1), 536-544.

Hurley, S. F., Jolley, D. J., \& Kaldor, J. M. (1997). Effectiveness of needle exchange programmes for prevention of HIV infection. Lancet, 349(9068), 1797-1800.

Jacobs, P., Calder, P., Taylor, M., Houston, S., Saunders, L. D., \& Albert, T. (1999). Cost effectiveness of Streework's needle exchange program of Edmonton. Canadian Journal of Public Health, 90(3), 168-171.

Loue, S., Lurie, P., \& Lloyd, L. S. (1995). Ethical issues raised by needle exchange programs. Journal of Law, Medicine \& Ethics, 23, 382-388.

Lurie, P., \& Chen, D. (1993). A review of programs in north America. In J. Stryker, \& M. D. Smith (Eds.), Dimensions of HIV prevention: needle exchange (pp. 11-33). Menlo Park, CA: Henry J. Kaiser Family Foundation.

Marmour, M., Shore, R. E., Titus, S., Chen, X., \& Des Jarlais, D. (2000). Drug injection rates and needle exchange use in New York City, 1991-1996. Journal of Urban Health, 77(3), 359-368.

Marx, M. A., Crape, B., Brookmeyer, R. S., Junge, B., Latkin, C., Vlahov, D., \& Strathdee, S. A. (2000). Trends in crime and the introduction of a needle exchange program. American Journal of Public Health, 90(12), 1933-1936.

Mateo, M. A. \& Kirchoff, K. T. (1999). Using and conducting nursing research in the clinical setting (2nd ed.). Philadelphia: Saunders.

Pearlman, D. C., Gournevitch, M. N., Trinh, C., Salomon, N., Horn, L., \& Des Jarlais, D. C. (2001). Cost-effectiveness of tuberculosis screening and observed prevention therapy for active drug users at a syringe exchange program. Journal of Urban Health, 78(3), 550-567. 
Portney, L. G., \& Watkins, M. P. (2000). Foundations of clinical research: applications to practice (2nd ed.). Upper Saddle River, NJ: Prentice Hall Health.

Reid, R. J. (2000). A benefit-cost analysis of syringe exchange programs. Journal of Health and Social Policy, 11(4), 41-57.

Van Ameijden, E. J., \& Coutinho, R. A. (2001). Large decline in injecting drug use in Amsterdam, 1986-1998: explanatory mechanisms and determinants of injecting transitions.
Journal of Epidemiology and Community Health, 55(5), 356-363.

Watters, J. K., Estilo, M. J., Clark, G. L., \& Lorvick, J. (1994). Syringe and needle exchange as HIV/AIDS prevention for injection drug users. The Journal of the American Medical Association, 271(2), 115-120.

Webber, D. W. (1997). AIDS and the law (3rd ed.). New York: Wiley. 